\title{
The effects of gas cooling on removal of SOF and sulphate by electrostatic precipitator for marine diesel
}

\author{
A. Zukeran ${ }^{1}$, Y. Sakuma ${ }^{1}$, R. Yamagami ${ }^{1}$, Y. Kawada ${ }^{2}$, \\ H. Kawakami ${ }^{3}$, K. Yasumoto $^{3}$, T. Inui ${ }^{3} \&$ Y. Ehara ${ }^{4}$ \\ ${ }^{1}$ Department of Electrical and Electronic Engineering, \\ Kanagawa Institute of Technology, Japan \\ ${ }^{2}$ Polytechnic University, Japan \\ ${ }^{3}$ Fuji Electric Co., Ltd., Japan \\ ${ }^{4}$ Department of Electrical and Electronic Engineering, \\ Tokyo City University, Japan
}

\begin{abstract}
Particulate matters (PM), SOx and NOx in exhaust gases emitted from marine diesel engines may cause serious problems in human health and coastal environments. Therefore, their emissions have been regulated in MARPOL Treaty 73/78 Annex VI of IMO Air Pollution Control since 2005. In this paper, the reduction of PM for marine engines was investigated using an electrostatic precipitator (ESP) with a heat exchanger. Experiments were carried out to confirm the reduction of PM, which were Dry soot, Soluble Organic Fraction (SOF) and sulphate. The experimental system consisted of a diesel engine, a heat exchanger and an ESP. The exhaust gas at a temperature of $180^{\circ} \mathrm{C}$ was cooled to $20^{\circ} \mathrm{C}$ in the heat exchanger, whereby particles of SOF and sulfuric acid were generated due to condensation. These particles were collected in the ESP. The particle concentrations were measured using a low-volume air sampler, a soxhlet extractor and an ion chromatograph. As a result, the gaseous SOF was condensed to particulate matter due to gas cooling. This particulate matter was collected by ESP, whose removal efficiency exceeded $85 \%$. The removal efficiency of sulphate was also improved.
\end{abstract}

Keywords: marine diesel, electrostatic precipitator, particulate matter, soluble organic fraction, sulphate. 


\section{Introduction}

Particulate matters (PM), SOx and NOx in the exhaust gases emitted from marine diesel engines may cause serious problems in human health and coastal environments. Therefore, their emissions have been regulated in MARPOL Treaty 73/78 Annex VI of IMO Air Pollution Control since 2005. The regulation typically requires the use of low-sulfur fuel to reduce the sulphate portion of PM emissions and SOx emissions. To reduce PM and SOx emissions, the Annex stipulates that the global sulphur fuel limit should be lowered to $3.5 \%$ in 2012 and further down to $0.5 \%$ in 2020 or 2025 . Alternatively, it is also permitted to use an exhaust gas cleaning aftertreatment system or similar machinery that can reduce emissions to the levels that should be achieved by using a low-sulfur fuel [1].

Seawater scrubbers for reduction of PM and SOx have begun to be installed on ships in Europe. However, there are still unsolved problems, such as the need for an extensive installation area on ships and a large amount of seawater. To improve the SOx removal efficiency, Nishida et al. investigated the technique of reducing SOx and NOx by alkali water and acid water generated by electrolysis of seawater [2]. Herrera et al. conducted research on waste water disposal by coffee-based powder activated carbon on seawater scrubbers [3]. On the other hand, the problem of PM compositions has also been reported. It is known that PM includes Dry soot, sulphate and soluble organic fraction (SOF) [4]. Electrostatic precipitators (ESP) have been developed for the removal of PM [57]. The reductions of $\mathrm{PM}, \mathrm{SOx}$ and NOx using plasma and chemical technologies have been investigated $[8,9]$.

In this study, a novel PM removal system for marine engines is proposed. Experiments were carried out to reduce PM, which were Dry soot, sulphate and SOF, by a gas heat exchanger and the ESP. The particle concentrations were measured by using a low volume air sampler, a soxhlet extractor and an ion chromatograph. The reduction amount and efficiency of sulphate, SOF and Dry soot were investigated.

\section{Principle of reduction of $\mathrm{SOF}$ and $\mathrm{SO}_{4}{ }^{2-}$}

The principle of reduction of SOF and $\mathrm{SO}_{4}{ }^{2-}$ is shown in Fig. 1. Sulphate and sufuric acid concentration are estimated by amount of $\mathrm{SO}_{4}{ }^{2-}$. The system consists of a heat exchanger and an ESP. The exhaust gas at a temperature between 160 and $240^{\circ} \mathrm{C}$ includes Dry soot as particulate matter and $\mathrm{H}_{2} \mathrm{O}, \mathrm{SOF}$, and $\mathrm{SO}_{2}$ as a part of gas. It is cooled to $30^{\circ} \mathrm{C}$ in the heat exchanger, whereby $\mathrm{H}_{2} \mathrm{O}$ mist and SOF particles are generated due to condensation. Sulfuric acid $\left(\mathrm{H}_{2} \mathrm{SO}_{3}\right.$ or $\left.\mathrm{H}_{2} \mathrm{SO}_{4}\right)$ is generated due to reaction between $\mathrm{H}_{2} \mathrm{O}$ mist and $\mathrm{SO}_{2}$. The PMs including sulphate, SOF, Dry soot and sulfuric acid are charged by a corona discharge, and then these are collected by electrostatic force in the ESP. 


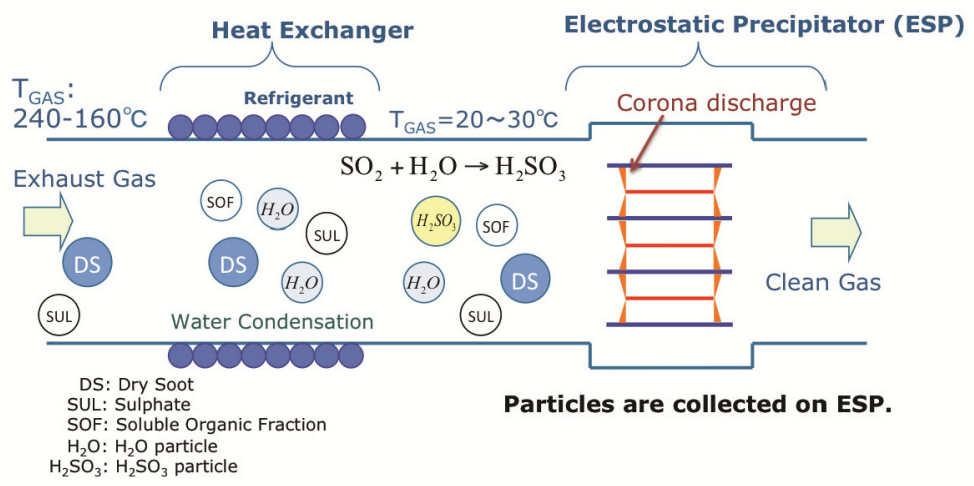

Figure 1: Principle of reduction of $\mathrm{SOF}$ and $\mathrm{SO}_{4}{ }^{2-}$.

\section{Experimental setup}

A schematic diagram of the experimental system is shown in Fig. 2. The system consists of the diesel engine, the heat exchanger and the electrostatic precipitator (ESP). Emissions from a diesel engine generator (Denyo, DA-3100SS-IV, displacement volume of $400 \mathrm{cc}$ ) using residual fuel oil (ENEOS, LSA 01) with $100 \%$ load were used. The refrigerant of the heat exchanger is water.

The structure of the ESP is shown in Fig. 3. The ESP has high voltage spikeplate electrodes and grounded plate electrodes. The spacing between the adjacent plates was $9 \mathrm{~mm}$, the grounded electrodes were $150 \mathrm{~mm}$ long, and the high voltage electrodes were $130 \mathrm{~mm}$ long. The applied voltages were between DC -4.0 and $-10.5 \mathrm{kV}$ (corona currents were between 0.0 and $4.3 \mathrm{~mA}$, and current densities were between 0 and $11.7 \mathrm{~mA} / \mathrm{m}^{2}$ ).

The PM concentrations in the gas were measured by a low volume air sampler. A part of the flue gas was sampled on the upstream and downstream sides of the ESP, and then PM was collected on Teflon filter (Tokyo Dylec, TX40HI20-WW) in the holder as shown in Fig. 2. The sampling tube was heated to the same temperature as the gas temperature by the tape heater to prevent condensation in the tube. The total PM concentration $\mathrm{C}_{\mathrm{PM}}$ was calculated by equation (1):

$$
C_{P M}=\left(M_{P M}-M_{f}\right) /\left(Q_{L} \cdot t\right)
$$

where $M_{P M}$ is a mass of the filter with the sampled PM, $M_{f}$ is a mass of the filter before sampling PM, $Q_{L}$ is the sampling gas flow rate $(16.7 \mathrm{~L} / \mathrm{min})$ and $t$ is the sampling time $(1 \mathrm{~min})$. The filter mass was measured after drying it for 2 hours at $50^{\circ} \mathrm{C}$.

After measuring the total $\mathrm{PM}$ concentration, $\mathrm{SOF}$ and $\mathrm{SO}_{4}{ }^{2-}$ concentrations were measured. SOF collected on the filter was separated by dichloromethane 
using a soxhlet extractor, and then SOF concentration $C_{S O F}$ was estimated from the measured mass of the filter as follows:

$$
C_{S O F}=\left(M_{D P M}-M_{e x t}\right) /\left(Q_{L} \cdot t\right)
$$

where $M_{\text {ext }}$ is a mass of the filter from which SOF was separated.

$\mathrm{SO}_{4}{ }^{2-}$ concentration was measured to estimate sulphate and sulfuric acid concentrations. $\mathrm{SO}_{4}{ }^{2-}$ on the filter was separated into ultra pure water (electrical conductivity: $1.7 \mathrm{~S} / \mathrm{cm}$ ) by an ultrasonic cleaner after measuring the SOF concentration. $\mathrm{SO}_{4}{ }^{2-}$ concentration $C_{\mathrm{SO} 4}$ was estimated by measuring the $\mathrm{SO}_{4}{ }^{2-}$ amount in the water with an ion chromatograph. The concentration of bound water $C_{B W}$ with sulfuric acid was defined as equal to 1.3 times [10] $\mathrm{SO}_{4}{ }^{2-}$ concentration $C_{\mathrm{SO} 4}$.

Dry soot concentration $C_{D S}$ was calculated as follows:

$$
C_{D S}=C_{P M}-C_{S O F}-C_{S O 4}-C_{B W}
$$

The reduction amounts and the reduction rates of $\mathrm{SO}_{4}{ }^{2-}, \mathrm{SOF}$, Dry soot and $\mathrm{PM}$ were estimated to investigate the effect of the gas-cooling on the efficiency of ESP. $\mathrm{SO}_{4}{ }^{2-}$ reduction amount $\Delta C_{\mathrm{SO}-\mathrm{V}}$ and the reduction rate $\eta_{\mathrm{SO} 4-\mathrm{V}}$, when the voltage of $V \mathrm{kV}$ was applied in the ESP, were calculated by equations (4) and (5):

$$
\begin{aligned}
& \Delta C_{S O 4-V}=C_{S O 4-0}-C_{S O 4-V} \quad\left[\mathrm{mg} / \mathrm{m}^{3}\right] \\
& \eta_{S O 4-V}=\left(\Delta C_{S O 4-V} / C_{S O 4-0}\right) \times 100[\%]
\end{aligned}
$$

where $C_{\mathrm{SO} 4-0}$ is $\mathrm{SO}_{4}{ }^{2-}$ concentration on the downstream side of the ESP at the voltage of $0 \mathrm{kV}$, and $C_{S O 4-V}$ is the concentration at $V \mathrm{kV}$.

The reduction amounts $\Delta C_{S O F-V}, \Delta C_{D S-V}, \Delta C_{P M-V}$ and the reduction rates $\eta_{S O F-V}$, $\eta_{D S-V}, \eta_{P M-V}$ of SOF, Dry soot and PM were also calculated similarly to (4) and (5). These concentrations were measured at the duct 3 as shown in Fig. 2.

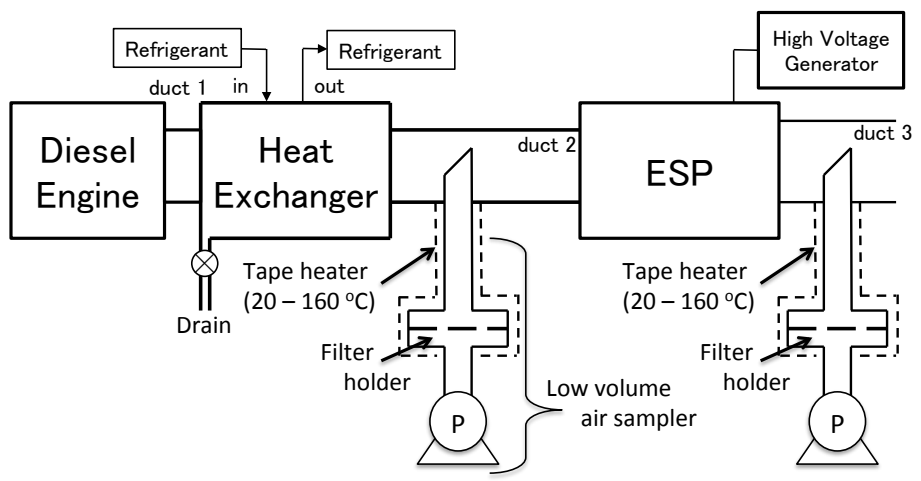

Figure 2: Schematic diagram of the experimental system. 

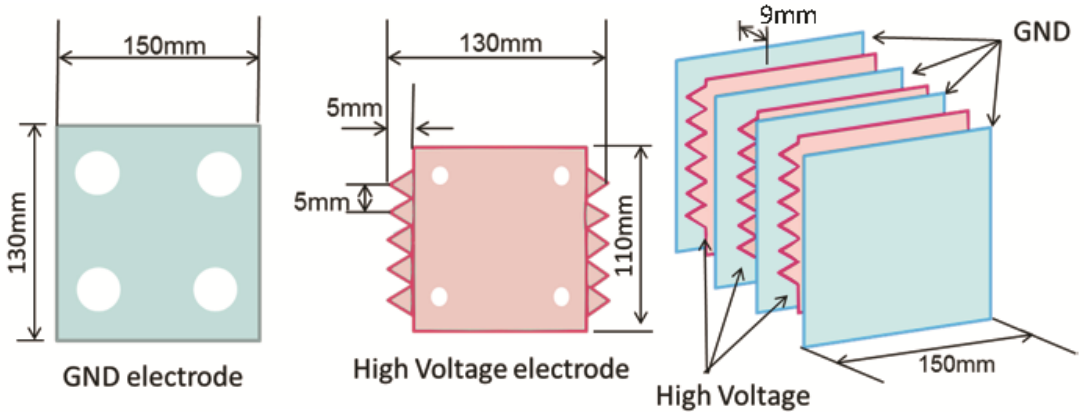

Figure 3: $\quad$ Structure of the ESP.

\section{Result and discussion}

The relationship between the composition of PM and the gas temperature is shown in Fig. 4. These were measured at the duct 2 as shown in Fig. 2. The concentrations are expressed in weight per unit volume $\left(1 \mathrm{~m}^{3}\right)$. The gas at $160^{\circ} \mathrm{C}$ had an $\mathrm{SO}_{4}{ }^{2-}$ content of $5.5 \mathrm{mg} / \mathrm{m}^{3}$, bound $\mathrm{H}_{2} \mathrm{O}$ content of $7.2 \mathrm{mg} / \mathrm{m}^{3}$, SOF content of $3.3 \mathrm{mg} / \mathrm{m}^{3}$ and Dry-soot content of $10.8 \mathrm{mg} / \mathrm{m}^{3}$. The concentrations of $\mathrm{SO}_{4}{ }^{2-}$, bound $\mathrm{H}_{2} \mathrm{O}$ and Dry soot did not significantly change with decreasing gas temperature. However, the SOF concentration significantly increased at $70^{\circ} \mathrm{C}$ or lower. This is probably because gaseous SOF forms particles due to

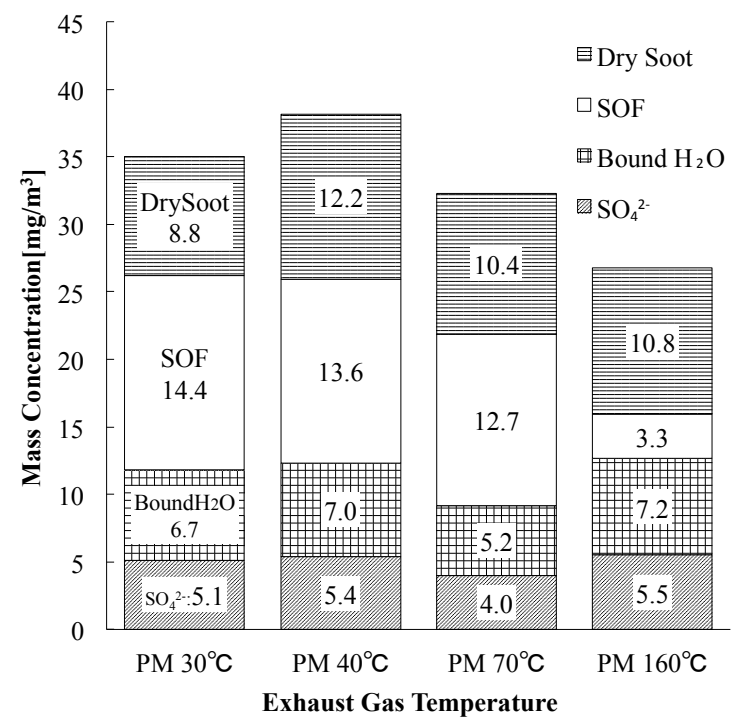

Figure 4: Relationship between the composition of PM and the gas temperature. 
condensation. Although the gaseous SOF is difficult to reduce, particulate SOF is easily collected by ESP. Condensation of $\mathrm{H}_{2} \mathrm{O}$ mist into liquid water was also confirmed [11].

The voltage-current relationship for various gas temperatures in ESP is shown in Fig. 5. The corona onset voltages were approximately $-4 \mathrm{kV}$. Although the corona current increased with increasing voltage, the current at the same voltage decreased at lower temperatures due to the decrease in electron energy.

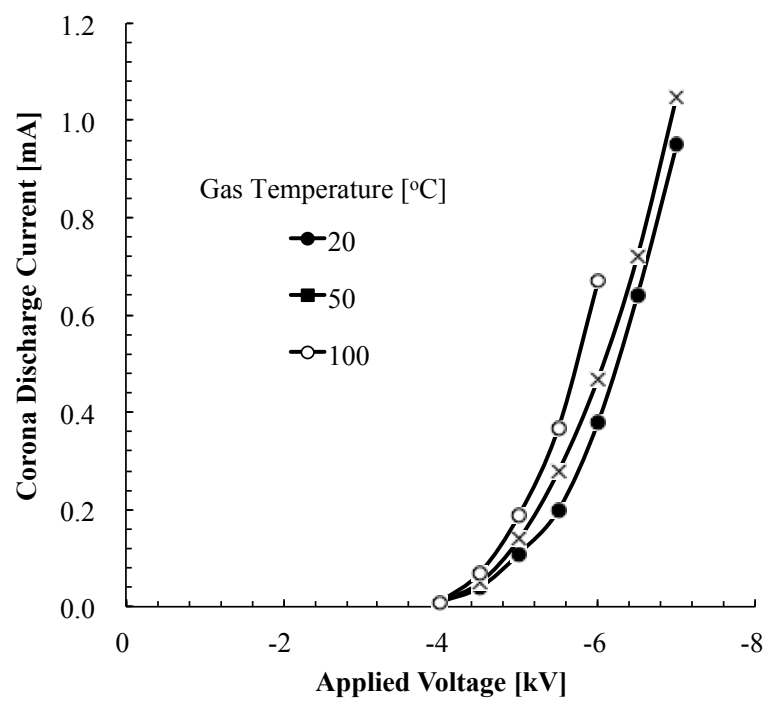

Figure 5: Voltage-current relationship for various gas temperatures.

The effect of reduction of PM in ESP was investigated. $\mathrm{SO}_{4}{ }^{2-}$ reduction amount $\Delta C_{\mathrm{SO} 4}$ as a function of applied voltage in ESP is shown in Fig. 6. $\mathrm{SO}_{4}{ }^{2-}$ was not reduced at $160^{\circ} \mathrm{C}$. On the other hand, the amount increased as the voltage increased and reached $4.1 \mathrm{mg} / \mathrm{m}^{3}$ at $30^{\circ} \mathrm{C}$ and $-7 \mathrm{kV}$. The reduction rate $\eta_{\mathrm{SO} \text { - } \mathrm{V}}$ as a function of the voltage is shown in Fig. $7 . \mathrm{SO}_{4}{ }^{2-}$ reduction rate at $160^{\circ} \mathrm{C}$ was lower than $15 \%$ for any voltages. The rate exceeded $85 \%$ at $30^{\circ} \mathrm{C}$, when the voltage at $-7 \mathrm{kV}$ was applied to the ESP. These results show that cooling the exhaust gas is effective for collecting sulphate by ESP. Negative amounts and rates means that the concentrations increase compared with the voltage of $0 \mathrm{kV}$. This cause is under investigation.

SOF reduction amount $\Delta C_{S O F}$ as a function of applied voltage in ESP is shown in Fig. 8. SOF reduction amount at $160^{\circ} \mathrm{C}$ tended to increase as the voltage increased, and that was $2.4 \mathrm{mg} / \mathrm{m}^{3}$ at $-6.5 \mathrm{kV}$. However, the amount at $30^{\circ} \mathrm{C}$ increased with increasing voltage due to the charge, and that was $8.0 \mathrm{mg} / \mathrm{m}^{3}$ at $-6.5 \mathrm{kV}$ or higher. This is because the SOF concentration increases due to condensation, as shown in Fig. 4. SOF reduction rate $\eta_{S O F-V}$ as a function of applied voltage is shown in Fig. 9. SOF reduction rate increased with increasing voltage and decreasing temperature. This result shows that SOF particulate is easy to be charged at low temperatures. 


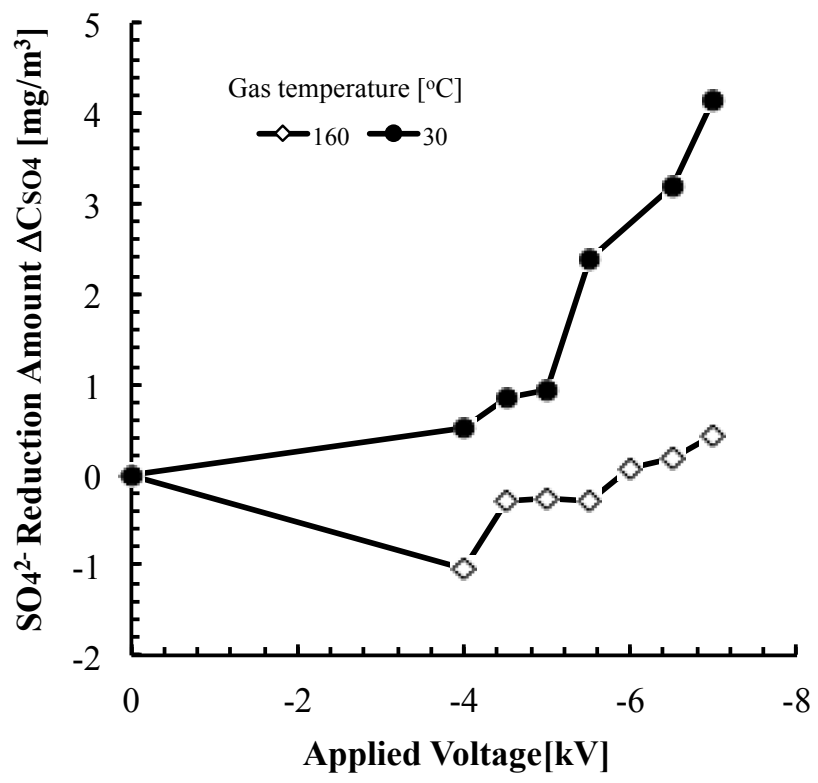

Figure 6: $\mathrm{SO}_{4}{ }^{2-}$ reduction amount $\Delta C_{\mathrm{SO} 4}$ as a function of applied voltage in ESP.

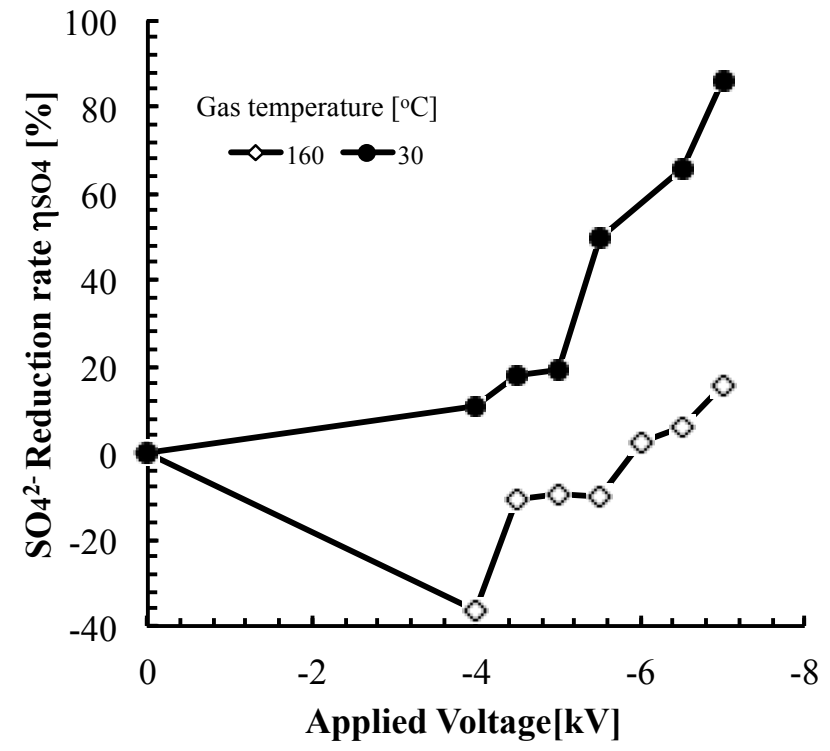

Figure 7: Reduction rate $\eta_{S O 4-V}$ as a function of applied voltage in ESP. 


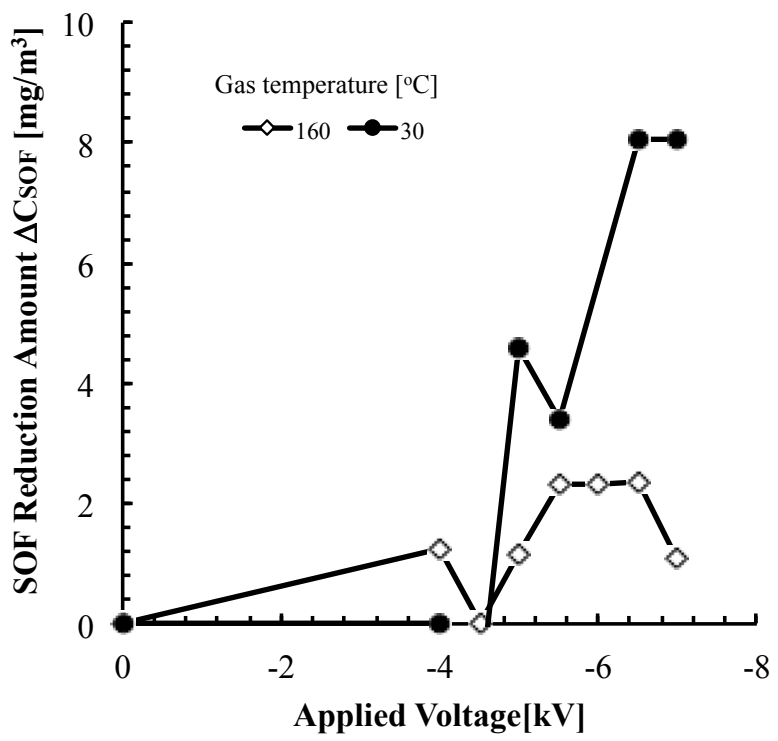

Figure 8: SOF reduction amount $\Delta C_{S O F}$ as a function of applied voltage in ESP.

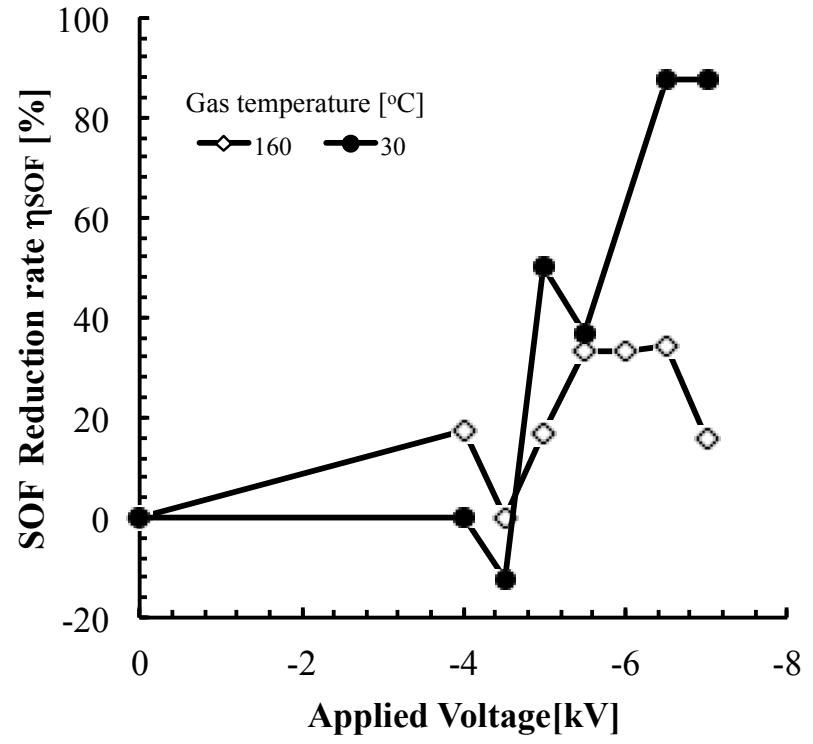

Figure 9: $\quad$ SOF reduction rate $\eta_{S O F-V}$ as a function of applied voltage in ESP. 
Dry soot reduction amount $\Delta C_{D S-V}$ as a function of applied voltage is shown in Fig. 10. Dry soot reduction amount increased with increasing voltage. However, the effect of the gas cooling was not confirmed. This is because the Dry soot concentration is not influenced by the temperature, as shown in Fig. 4. The Dry soot reduction rate $\eta_{D S-V}$ as a function of applied voltage is shown in Fig. 11. The efficiency was expressed in $100 \%$, when the reduction amount was greater than the concentration in the gas. The Dry soot reduction rate increased with increasing voltage, and high efficiencies were achieved at both temperatures.

The total PM reduction amount $\Delta C_{P M-V}$ as a function of applied voltage is shown in Fig. 12. The total PM reduction amount also increased with increasing voltage. The reduction amount at $160^{\circ} \mathrm{C}$ was lower than the amount at $30^{\circ} \mathrm{C}$. The total PM reduction rate $\eta_{P M-V}$ as a function of applied voltage is shown in Fig. 13. The rate at $160^{\circ} \mathrm{C}$ was no more than $57 \%$, whereas the rate at $30^{\circ} \mathrm{C}$ reached $87 \%$. These results indicate that the gas-cooling process helps improving the removal effect of harmful substances from marine diesel by ESP.

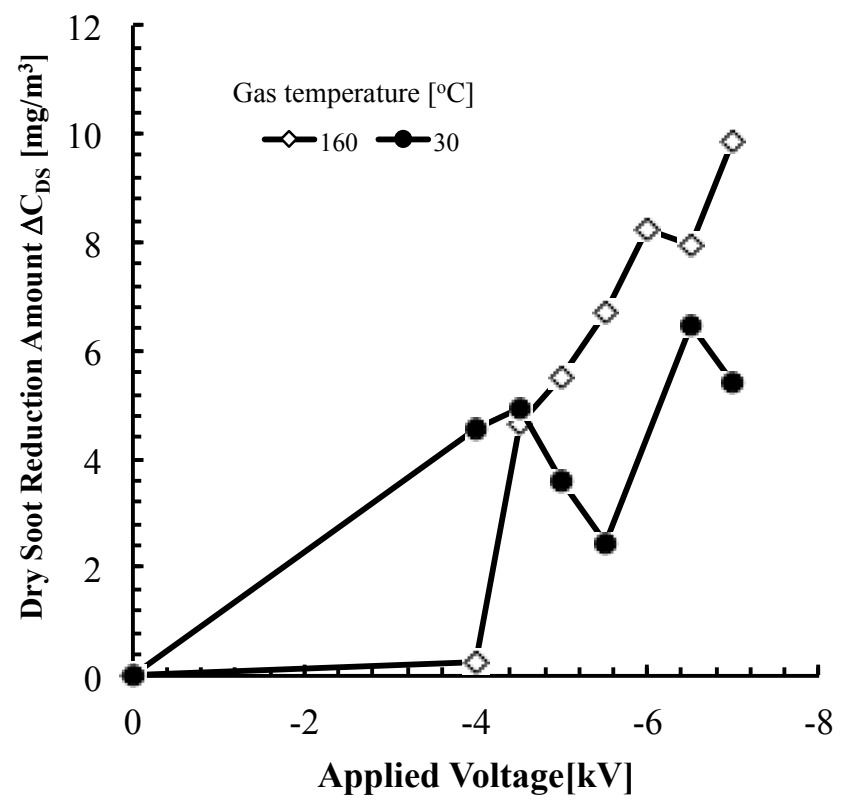

Figure 10: Dry soot reduction amount $\Delta C_{D S-V}$ as a function of applied voltage in ESP. 


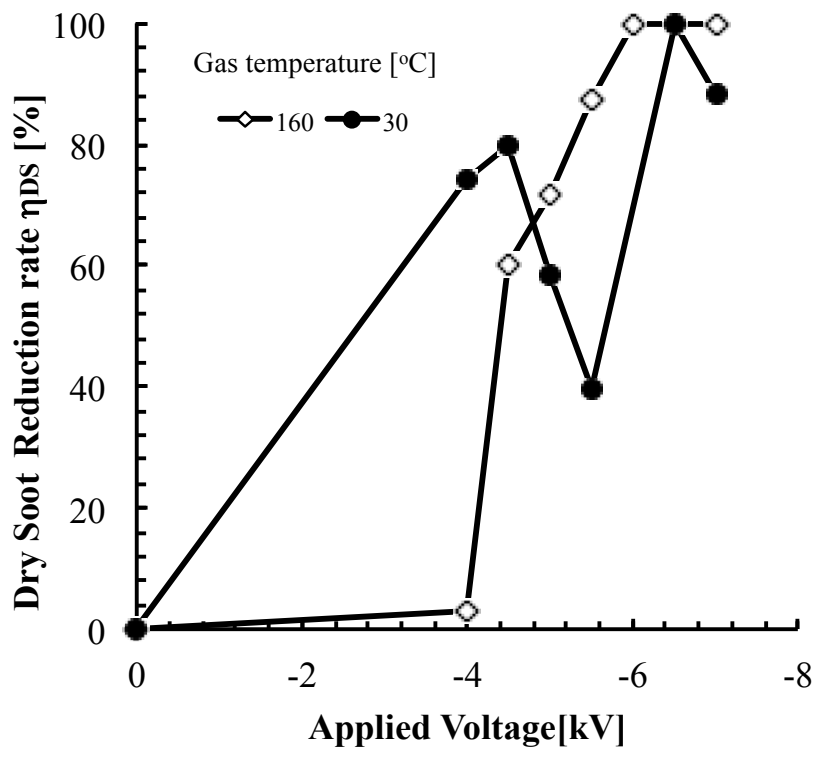

Figure 11: Dry soot reduction rate $\eta_{D S-V}$ as a function of applied voltage in ESP.

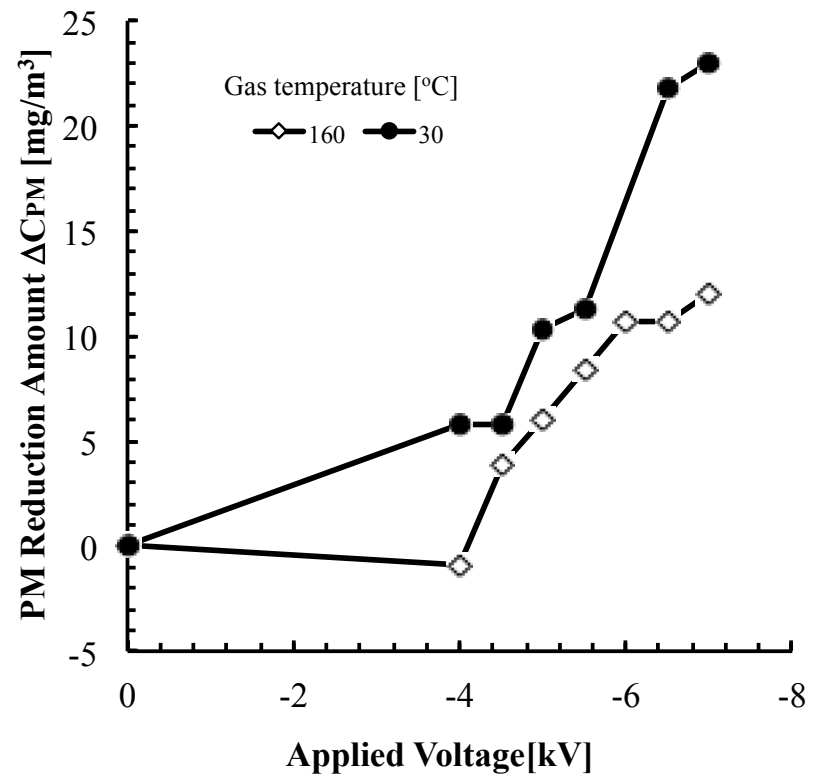

Figure 12: Total PM reduction amount $\Delta C_{P M-V}$ as a function of applied voltage in ESP. 


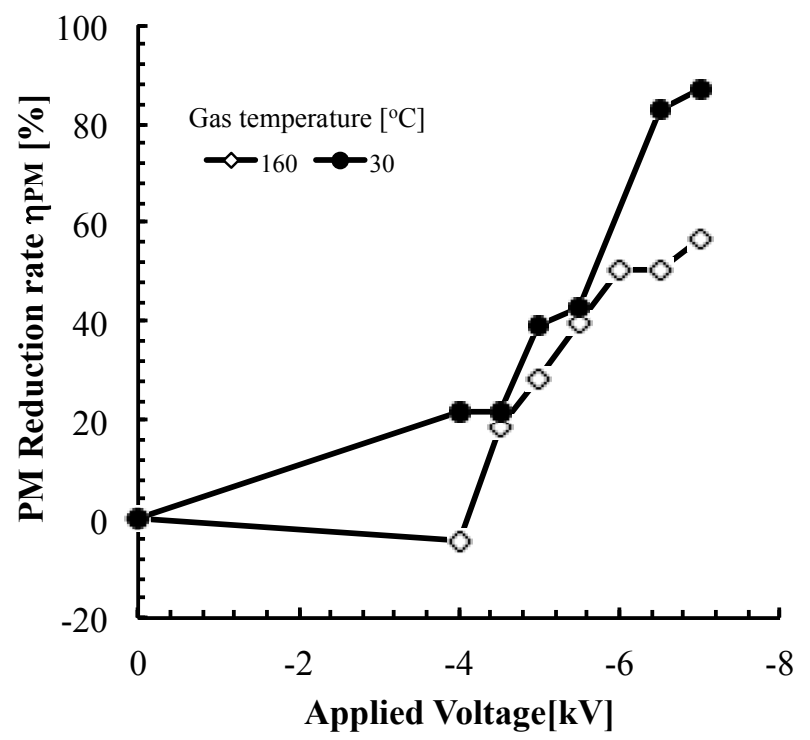

Figure 13: Total PM reduction rate $\eta_{P M-V}$ as a function of applied voltage in ESP.

\section{Conclusion}

In this study, a novel PM removal system for marine engines has been proposed. Experiments were carried out to reduce PM, which were Dry soot, sulphate and SOF, by a gas heat exchanger and the ESP. Results are follows;

1) $\mathrm{PM}$ concentration in the exhaust gas increases, when the gas is cooled to $30^{\circ} \mathrm{C}$ from $160^{\circ} \mathrm{C}$. This is because particulate SOF concentration increases due to condensation.

2) Cooling the exhaust gas is effective for collecting sulphate and SOF as part of particulate matter by ESP.

3) Dry soot is easy to collect at temperatures between $30^{\circ} \mathrm{C}$ and $160^{\circ} \mathrm{C}$ by ESP.

\section{Acknowledgement}

This work was supported by a Grant-in-Aid for Scientific Research (B), No. 24360361, from the Japan Society for the Promotion of Science.

\section{References}

[1] American Bureau of Shipping (ABS), "Exhaust Gas Scrubber Systems, Status and Guidance" 
[2] Osami Nishida, Hirotsugu Fujita, Wataru Harano, Hendratna Karika Kus, I Made Ariana, Ryo Kawazoe, Megumi Fujio, "New System for 80\% Reduction of Marine NOx, SOx and PM", Journal of the JIME, Vol. 44, No. 1, pp. 95-103, 2009.

[3] Nimia Herrera, Osami Nishida, Hirotsugu Fujita, Wataru Harano, Houng Soo Kim, Takashi Ohgawara, "Waste Water Disposal by Coffee-based Powder Activated Carbon on Seawater Scrubber System for Exhaust Gas Treatment", Journal of the JIME, Vol. 41, No. 5, pp. 119-124, 2006.

[4] Kazuyuki Maeda, Koji Takasaki, Kazuhiro Masuda, Minoru Tsuda, Mikio Yasunari, "Measurement of PM emission from marine diesel engines", CIMAC Congress 2004, Kyoto, Paper No. 107, 2004.

[5] I Made Ariana, Osami Nishida, Hirotsugu Fujita, Wataru Harano, Megumi Fujio, "Development of Electrostatic Precipitator to Reduce Marine Diesel Particulate Matter”, Journal of JIME, Vol. 42, No. 2, pp. 122-128, 2007.

[6] Toshiaki Yamamoto, Takuya Mimura, Naoyuki Otsuka, Yoshikazu Ito, Yoshiyasu Ehara, Akinori Zukeran, "Diesel PM Collection for Marine and Automobile Emissions Using EHD Electrostatic Precipitators", IEEE Trans. Ind. Appl., Vol. 46, No. 4, pp. 1606-1611, 2010.

[7] H. Kawakami, A. Zukeran, K. Yasumoto, T. Inui, Y. Ehara, T. Yamamoto, "Diesel PM Collection for Marine Emissions Using Double Cylinder Type Electrostatic Precipitator", Int. J. Plasma Environ. Sci. \& Tech., Vol. 5, No. 2, pp. 174-178, 2011.

[8] T. Urabe, Y. Wu, M. Ono, S. Masuda, "Experimental Study on NOx and SOx Removal by Pulse Corona Discharge", Journal of the Institute of electrostatics Japan, 12, 5, 354-359, 1988.

[9] T. Yamamoto, M. Okubo, T. Nagaoka, K. Hayakawa, "Simultaneous Removal of NOx, SOx, and $\mathrm{CO} 2$ at Elevated Temperature Using a Plasma-Chemical Hybrid Process", IEEE Trans. on Ind. Appl. Vol. 38, No. 5, pp. 1168-1173, 2002.

[10] J. C. Wall, S. K. Hoekman; Fuel Composition Effects on Heavy-Duty Diesel Particulate Emissions, SAE Technical Paper Series, 841364, 1984.

[11] Akinori Zukeran, Kazuya Ninomiya, Yoshiyasu Ehara, Koji Yasumoto, Hitomi Kawakami, Takashi Inui, "SOx and PM removal using electrostatic precipitator with heat exchanger for marine diesel", 2013 Annual meeting of the Electrostatic Society of America, K4, 2013. 